Colin James Smithells, Metals reference book. 3rd edit. 2 vols. London: Butterworths. 1962. 1: (XVI + $568 ; 17 \mathrm{S.}) 2$ : (XVI + $519 \mathrm{~S} ; 17 \mathrm{~S}.) 10 £ 10 \mathrm{~s}$.

E. Tricot, Formulaire du métallurgiste. Paris: Gauthier-Villars. 1962. (70 S.) 5 NF.

Robart George Ward, An introduction to the physical chemistry of iron and steel making. London: Edward Arnold. 1962. (IX + $238 \mathrm{~S}$. m. Tab. u. Diagr.) 42 s.

-., Hydrogen in steel: papers and discussions, Harrogate conference, October 1961. London: Iron \& Steel Institute. 1962. (154 S. m. Abb., Tab. u. Diagr.) $25 \mathrm{~s}$.

- Symposium on evaluation of metallic materials in design for low-temperature service; presented at the sixty-fourth annual meeting Amer. Society for Testing and Materials, Atlantic City, New Jersey, June 27-28, 1961. Philadelphia: ASTM. 1962. (245 S. m. Abb.) \$7,50.

G. M. Borodulin, The Use of Oxygen in the Electrometallurgy of Steel. (Ubersetzung aus dem Russischen.) Oxford, London, New York, Paris: Pergamon Press 1961. (VII + 112) $50 \mathrm{~s}$.

Es wird die Herst. von Blektrostahl unter Verw. von $\mathrm{O}_{2}$ in sowjet. Stahlwerken, Technologie, Eigg. der erschmolzenen rostfreien Stăhle, Kugellager-, Transformatoren-, Werkzeug-, Schnelldreh- u. Schutzmaßnahmen für die Schmelzer beschrieben.

$\mathrm{H}_{16}$. Nahrungs., Genuß- und Futtermittel

Peter Pletz und Erwin Hettwer, Stecoritten, ein neues Desinfektionsmittel in der Lebensmittelindustrie. Nürnberg: Carl. 1962. (16 S.) $8^{\circ}=$ Bibliotheca lactis 84. DM 1,50.

$\mathrm{H}_{10}$. Brennstoffe. Erdöl. Mineralöle

Vittorio Bianchl e Massimo Fossatl, I punti vendita di carburanti. Guida pratica della regolamentazione tecnico-gluridica ed amministrativa per l'installazione e l'esercizio commerciale dei distributori di carburanti. Genova: Codice del petrolio. 1961. (XX +129 S. m. Abb.) L. 1500.-.

\title{
Ausgewertete Bibliographie-Fachzeitschriften
}

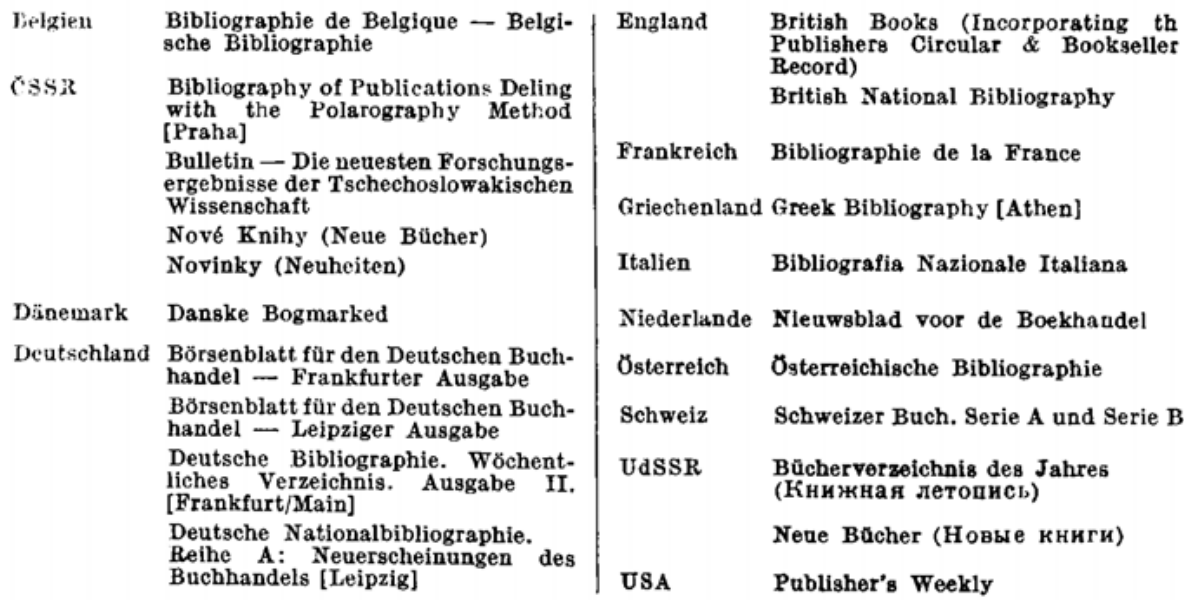


